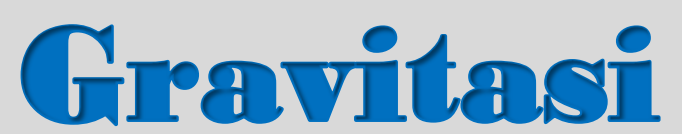

Journal available at: https://bestjournal.untad.ac.id/index.php/GravitasiFisika e-ISSN: 2654-4318 p-ISSN: 1412-2375

\title{
Perbandingan Metode Contrast Enhancement pada Citra CT-Scan Kanker Paru-paru
}

\author{
(Comparison of Contrast Enhancement on CT-Scan Images of Lung Cancer)
}

\author{
Nurhidayah $^{1}$, Bannu A. Samad ${ }^{1 *}$ dan B. Abdullah ${ }^{1}$ \\ ${ }^{1)}$ Departemen Fisika, Universitas Hasanuddin
}

\section{Info}

\section{Article history:}

Received: 05 Desember 2020

Accepted: 18 Desember 2020

Published: 31 Desember 2020

\begin{abstract}
Abstrak.
Di Indonesia kanker paru menjadi penyebab kematian kedua setelah kanker payudara. Angka mortalitas yang cukup tinggi, maka penentuan diagnosis lebih awal memegang peranan yang sangat penting dalam manajemen terapi. Kelemahan CT-Scan dalam mendiagnosa kanker paruparu disebabkan oleh kontras citra yang rendah dan derau pada citra. Pada penelitian ini akan membandingkan metode contrast enhancement berbasis histogram equalization dan contrast limited adaptive histogram equalization untuk meningkatkan kualitas citra dengan menggunakan software Matlab. Namun, sebelumnya dilakukan reduksi noise dengan menggunakan metode median filter. Kinerja dari setiap metode dihitung dengan mencari nilai MSE (Mean Square Error) dan PSNR (Peak Signal to Noise Ratio) citra. Dari nilai MSE dan PSNR diperoleh nilai MSE dan PSNR terbaik pada metode contrast limited adaptive histogram equalization dengan nilai 653,434 dB dan 245,547 dB
\end{abstract}

Abstract.

In Indonesia, lung cancer is the second leading cause of death after breast cancer. Since the mortality rate are quite high, so determining earlier diagnosis plays a very important role in the management of therapy. The weakness of CT-Scan in diagnosing lung cancer is caused by low image contrast and noise in the image. This research will compare with contrast enhancement methods based on histogram equalization and contrast limited adaptive histogram equalization to improve image quality using Matlab software. However, noise reduction was previously performed using median filter method. The performance of each method are calculated by finding the value of MSE (Mean Square Error) and PSNR (Peak Signal to Noise Ratio) image. From the MSE and PSNR values are obtained the best MSE and PSNR values in the contrast limited adaptive histogram equalization method with values $653,434 \mathrm{~dB}$ and $245,547 \mathrm{~dB}$, respectively.

\section{Kata kunci:}

Contrast Limited Adaptive Histogram Equalization

CT-Scan

Kanker paru-paru

\section{Keywords:}

Histogram Equalization

Contrast Limited Adaptive His-

togram Equalization

CT-Scan

Lung cancer

*) e-mail: bannu251973@gmail.com

DOI: $10.22487 /$ gravitasi.v19i2.15360

\section{PENDAHULUAN}

Kanker paru-paru merupakan salah satu penyebab mortalitas terbesar di dunia [1]. Berdasarkan data Word Cancer Report pada Tahun 2014, kanker paru-paru masih menjadi salah satu penyakit mematikan dengan angka kematian sekitar 1,2-1,56 juta setiap tahunnya. Diperkirakan angka kematian ini akan terus meningkat, dimana pada Tahun 2030 diperkirakan terdapat 17 juta angka kematian akibat kanker paru-paru [2]. Berdasarkan data Globocan Tahun 2012, di Indonesia kanker paru menjadi penyebab kematian kedua setelah kanker payudara yaitu sebanyak 15,9\% [3]. Angka mortalitas yang cukup tinggi, maka penentuan diagnosis lebih awal memegang peranan yang sangat penting dalam manajemen terapi [4].
CT-Scan merupakan salah satu modalitas yang digunakan untuk mengevaluasi dan mendiagnosis kanker paru-paru [5]. CT-Scan mampu menghasilkan gambar secara detail untuk setiap bagian tubuh manusia. Namun, beberapa kasus sering tidak ditemukan nodul kanker karena tertutupi oleh struktur anatomi atau akibat rendahnya kualitas citra. Pada dasarnya, CT-Scan mampu menghasilkan citra yang menunjukkan letak nodul kanker secara jelas dan detail. Tetapi apabila penyebab sulitnya mendiagnosa nodul kanker akibat rendahnya kualitas citra, maka kualitas citra perlu diperbaiki agar nodul kanker dapat terlihat jelas [6]. 
Salah satu cara memperbaiki kualitas citra yaitu dengan meningkatkan kontras citra (contrast enhancement). Selain meningkatkan kontras citra, diagnosis dari pemeriksaan CTScan dapat ditingkatkan dengan mereduksi noise salt and pepper karena citra juga dapat mengalami penurunan mutu yang disebabkan oleh derau (noise) [7]. Software Matlab menjadi salah satu program pengolahan citra yang berkembang pesat dalam beberapa tahun terakhir. Banyak dimanfaatkan di berbagai bidang. Salah satu pemanfaatannya dalam bidang medis yaitu dapat melakukan pengolahan citra untuk mendeteksi berbagai penyakit berbasis citra dengan menerapkan ilmu fisika dan bahasa komputasi [8].

Penelitian sebelumnya telah dilakukan oleh Singh, et. al. pada Tahun 2019 tentang peningkatan kualitas citra pada citra retina kontras rendah untuk deteksi dini retinopati diabetik dengan metode histogram equalization diperoleh kualitas citra yang baik dan sangat efisien digunakan pada citra kontras rendah [9]. Nasution pada Tahun 2019 melakukan penelitian tentang perbaikan kualitas citra dengan metode contrast limited adaptive histogram equalization pada citra maps diperoleh kualitas citra yang baik dengan tampilan nilai piksel yang lebih jelas [10]. Khilmawan dan Riadi pada Tahun 2018 melakukan penelitian tentang pengurangan noise pada citra tulang menggunakan metode median filter dan gaussian filter diperoleh metode median filter lebih baik dalam mereduksi noise [7]. Oleh karena itu, penelitian ini akan membandingkan metode peningkatan kontras (contrast enhancement) berbasis histogram equalization dan contrast limited adaptive histogram equalization yang dikombinasikan dengan metode median filter dalam mereduksi noise. Selanjutnya dilihat kinerja masing-masing metode, seberapa baik metode tersebut dapat dijadikan input untuk tahap selanjutnya (ekstraksi fitur dan klasifikasi). Kinerja masing-masing metode dapat dilihat dari nilai MSE dan PSNR dari metode tersebut.

\section{BAHAN DAN METODE}

\subsection{Alat dan Bahan}

Penelitian ini menggunakan 4 data citra CT-Scan dari 4 pasien kanker paru-paru. Data citra diperoleh di http://www.radiopedia.org berdasarkan slice dengan potongan aksial. Setiap citra diolah dengan menggunakan bantuan software Matlab 2017a.

\subsection{Metode Penelitian}

Penelitian ini dilaksanakan pada bulan Juni 2020 di Laboratorium Optik dan Spektroskopi Fisika, Departemen Fisika, Fakultas Matematika dan Ilmu Pengetahuan Alam, Universitas Hasanuddin, Makassar. Tahapan pada proses peningkatan kualiatas citra terdiri dari akuisisi citra, konversi citra RGB ke grayscale, reduksi noise dengan menggunakan metode median filter, pengujian peningkatan kontras berbasis histogram equalization dan contrast limited adaptive histogram equalization.

\subsubsection{Median Filter}

Metode median filter merupakan filter nonlinear yang berfungsi untuk mengurangi noise dan menghaluskan citra. Dikatakan nonlinear karena cara kerja penapis ini tidak termasuk kedalam kategori operasi konvolusi. Operasi nonlinear dihitung dengan cara mengurutkan nilai intensitas sekelompok piksel, kemudian mengganti nilai piksel yang diproses dengan nilai tertentu. Pada median filter suatu window atau penapis yang memuat sejumlah piksel digeser titik per titik pada seluruh daerah citra. Lalu nilai-nilai tersebut diurutkan secara ascending untuk kemudian dihitung nilai mediannya. Nilai median tersebut akan menggantikan nilai yang berada pada pusat bidang window [11].

\subsubsection{Histogram Equalization}

Metode histogram equalization akan meningkatkan kualitas citra digital dengan melakukan perataan histogram dimana penyebaran nilai tingkat keabuan citra dibuat rata [12]. Persamaan histogram equalization dapat dituliskan sebagai berikut [13]:

$$
\mathrm{S}_{\mathrm{k}}=\mathrm{T}\left(\mathrm{r}_{\mathrm{k}}\right)=(\mathrm{L}-1) \sum_{j=0}^{k} p_{r}\left(r_{j}\right)=\frac{L-1}{M N} \sum_{j=0}^{k} n_{j}
$$

Dimana MxN menunjukkan total jumlah piksel, L jumlah tingkat abu-abu, dan $\mathrm{p}_{\mathrm{r}}\left(\mathrm{r}_{\mathrm{j}}\right)$ jumlah piksel dalam gambar masukan dengan intensitas nilai $r_{j}$. Rentang nilai input dan output abu-abu berada di kisaran $0,1,2, \ldots, \mathrm{L}-1$. Kemudian, transformasi histogram equalization memetakan input nilai $\mathrm{r}_{\mathrm{k}}$ (di mana $\mathrm{k}=0,1,2, \ldots, \mathrm{L}-1$ ) hingga nilai output $\mathrm{S}_{\mathrm{k}}$ [13].

\subsubsection{Contrast Limited Adaptive Histogram Equalization}

Metode contrast limited adaptive histogram equalization akan meningkatkan kontras lokal citra dengan memberikan nilai batas pada histogram. Nilai batas ini disebut dengan clip limit yang menyatakan batas maksimum tinggi suatu histogram. Cara menghitung clip limit suatu histogram dapat didefinisikan dengan persamaan $[14,15]$ :

$$
\beta=\frac{M}{N}\left(1+\frac{\alpha}{100}(s-1)\right)
$$

Dimana $\mathrm{M}$ menunjukkan luas region size, $\mathrm{N}$ nilai grayscale (256), dan $\alpha$ clip factor (penambahan batas limit suatu histogram yang bernilai antara 0-100) [13].

\subsection{Analisis Data}

Mencari nilai Mean Square Error (MSE) dan Peak Signal to Noise Ratio (PSNR) untuk mengetahui metode mana yang lebih bagus untuk dipakai dalam peningkatan kualitas citra. Semakin kecil nilai MSE dan semakin besar nilai PSNR, maka semakin baik pula hasil yang diperoleh pada tampilan citra hasil. Nilai MSE dan PSNR dapat diperoleh melalui persamaan sebagai berikut [16] [17]:

$$
\mathrm{MSE}=\left(\frac{1}{M N} \sum_{x=0}^{M} \sum_{y=0}^{N}\left(g^{\prime}(x, y)-g(x, y)\right)^{2}\right)
$$

Dimana :

$$
\begin{array}{ll}
\mathrm{MSE} & =\text { Nilai mean square error dari citra } \\
\mathrm{M} & =\text { Panjang citra cover (dalam } \text { pixel }) \\
\mathrm{g}(\mathrm{x}, \mathrm{y}) & =\text { nilai pixel dari citra cover } \\
\mathrm{N} & =\text { Panjang citra stego (dalam pixel }) \\
\mathrm{g}^{\prime}(\mathrm{x}, \mathrm{y}) & =\text { nilai pixel dari citra stego }
\end{array}
$$

Selanjutnya nilai PSNR dapat dihitung dari kuadrat nilai maksimu dibagi dengan MSE menurut persamaan :

$$
\text { PSNR }=10 \log _{10}\left(\frac{M a x^{2}}{M S E}\right)
$$

Dimana:

Nilai $\operatorname{Max}=$ nilai maksimum dari pixel citra yang digunakan,

Semakin rendah nilai MSE maka semakin baik dan semakin besar nilai PSNR maka semakin baik kualitas citra steganografi. 
Berdasarkan ukuran efektifitas dari algoritma yang telah digunakan melalui perhitungan nilai MSE dan PSNR, maka akan dapat disimpulan tentang kualitas citra pada steganografi dengan algoritma Random Pixel Positioning.

\section{HASIL DAN PEMBAHASAN}

Pada penelitian ini digunakan software Matlab untuk melakukan pengujian peningkatan kontras pada citra CT-Scan kanker paru-paru. Sebagai batasan, citra yang digunakan berupa citra grayscale. Citra berwarna (citra RGB) terlebih dahulu dikonversi menjadi citra grayscale dan citra yang mengandung noise akan dilakukan proses untuk menghilangkan noise dengan menggunakan metode median filter, sehingga dapat dilakukan pengujian proses perbaikan kontras citra dengan menggunakan metode histogram equalization dan contrast limited adaptive histogram equalization. Keberhasilan metode peningkatan kualitas citra ini dapat diukur dengan teknik visual yaitu melihat pada citra hasil dan membandingkan dengan citra asli, tetapi dalam citra medis tidak mudah melihat kelainannya tanpa memiliki dasar pengetahuan yang baik karena hasil pengukuran teknik visual setiap orang berbeda-beda. Maka untuk mendapatkan output yang maksimal sebagai masukan untuk proses ekstraksi fitur dan klasifikasi, dilakukan perhitungan nilai MSE dan PSNR sebagai parameter keberhasilan metode. Adapun hasil yang diperoleh pada penelitian ini seperti pada Tabel 1 .
Tabel 1 menunjukkan metode histogram equalization cenderung untuk mengubah kecerahan rata-rata citra ke tingkat tengah rentang dinamis dan menghasilkan artifak dan efek intensitas saturasi. Hal ini disebabkan metode histogram equalization menghasilkan histogram yang seragam atau merata sehingga penggunaan metode ini akan menghasilkan histogram terlihat lebih melebar. Sedangkan pada metode contrast limited adaptive histogram equalization diperoleh struktur anatomi yang tidak ditampilkan pada citra asli lebih terlihat, nodul kanker juga terlihat lebih jelas, dan kontras citra yang dihasilkan lebih baik dibanding dengan metode histogram equalization. Hal ini disebabkan metode contrast limited adaptive histogram equalization memberikan nilai batas pada histogram. Nilai batas ini disebut dengan clip limit yang menyatakan batas maksimum tinggi suatu histogram sehingga dapat mengatasi peningkatan kontras citra secara berlebihan.

Gambar 1 menunjukkan metode histogram equalization diperoleh persebaran histogram citra hasil jauh lebih merata dibanding citra asli dengan histogram yang lebih merata maka akan meningkatkan persebaran nilai grayscale sehingga struktur terlihat lebih detail. Sedangkan metode contrast limited adaptive histogram equalization diperoleh histogram di atas nilai clip limit dianggap kelebihan (excess) piksel yang akan didistribusikan kepada area sekitar di bawah clip limit sehingga terlihat struktur yang lebih detail.

Tabel 1. Hasil Pengolahan Citra

Nama Citra

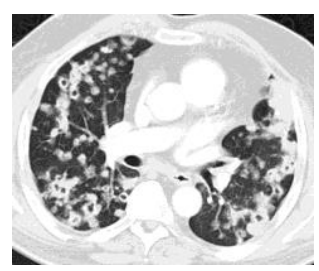

Citra2.jpg

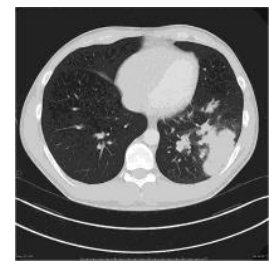

Citra3.jpg

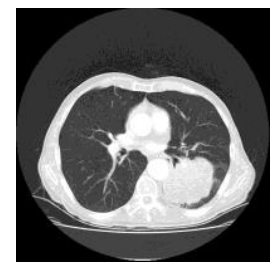

Citra4.jpg

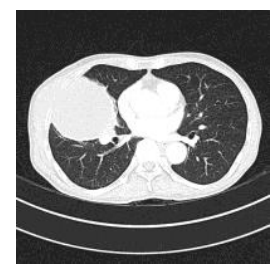

HE

CLAHE
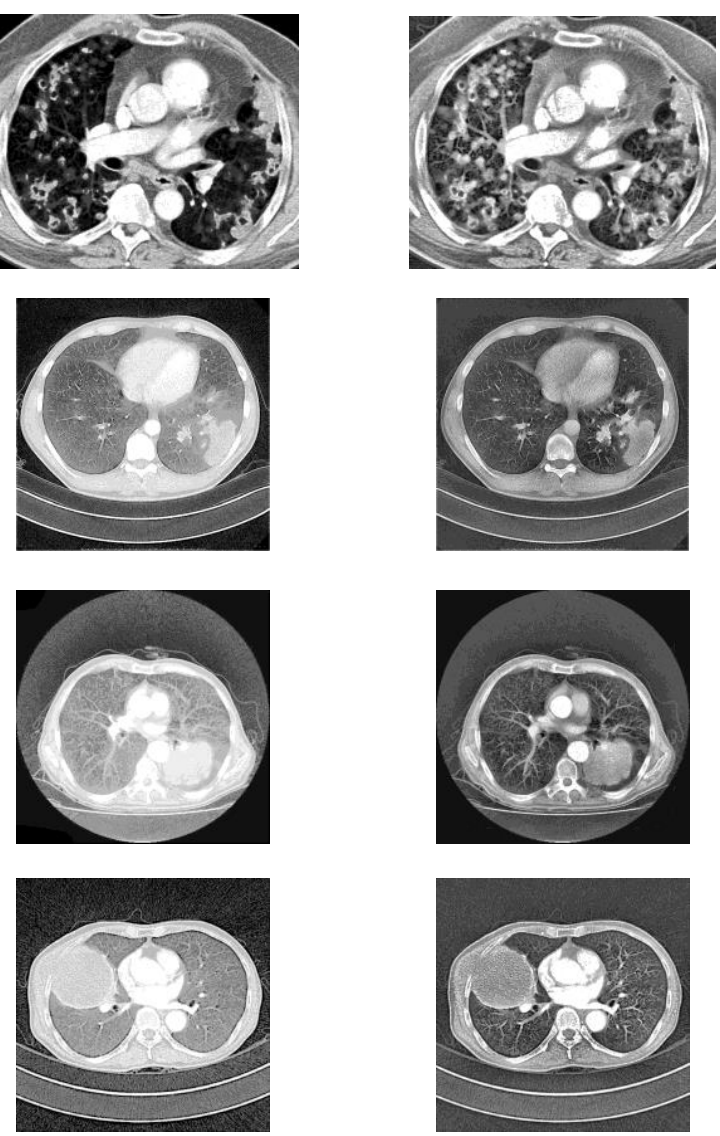
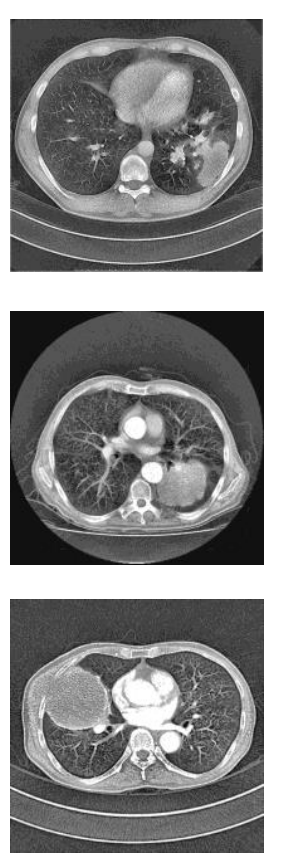

Keterangan :

$\mathrm{HE}=$ Histogram Equalization

CLAHE $=$ Contrast Limited Adaptive Histogram Equalization 


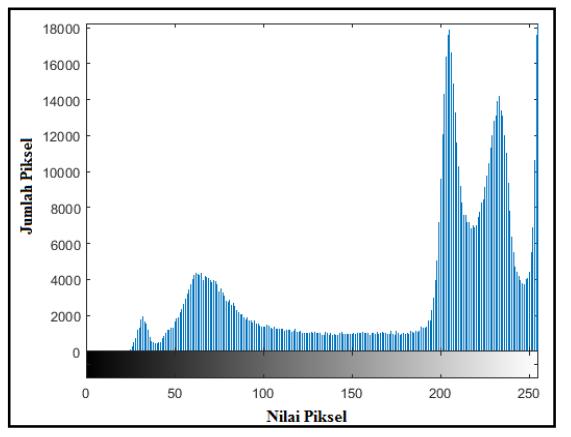

(a)

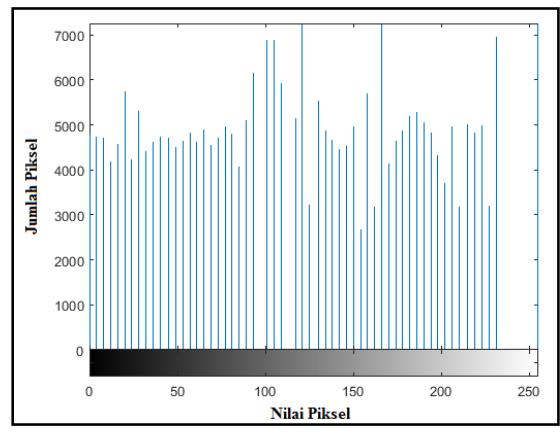

(b)

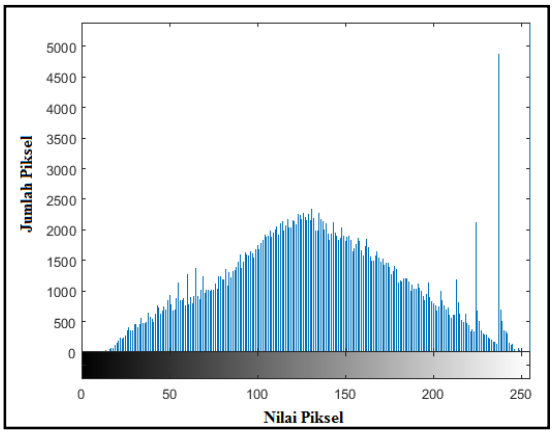

(c)

Gambar 1. (a) Histogram Citra Asli pada Citra 1, (b) Histogram Citra Hasil (Histogram Equalization) pada Citra 1, dan (c) Histogram Citra Hasil (Contrast Limited Adaptive Histogram Equalization) pada Citra 1

Tabel 2. Perbandingan Nilai MSE dan PSNR

\begin{tabular}{ccccc}
\hline Citra & $\begin{array}{c}\text { MSE } \\
(\text { HE) }\end{array}$ & $\begin{array}{c}\text { PSNR } \\
\text { (HE) }\end{array}$ & $\begin{array}{c}\text { MSE } \\
\text { (CLAHE) }\end{array}$ & $\begin{array}{c}\text { PSNR } \\
\text { (CLAHE) }\end{array}$ \\
\hline Citra 1 & $1.530,4$ & 150,091 & $1.171,2$ & 171,569 \\
Citra 2 & 757,336 & 213,359 & 467,181 & 271,652 \\
Citra 3 & 886,593 & 197,194 & 396,189 & 294,988 \\
Citra 4 & 625,512 & 234,768 & 579,165 & 243,980 \\
\hline Rata-rata & 949,960 & 198,853 & 653,434 & 245,547
\end{tabular}

Keterangan :

$\mathrm{HE}=$ Histogram Equalization

CLAHE $=$ Contrast Limited Adaptive Histogram Equalization

Pada Tabel 2 menunjukkan perbandingan nilai MSE dan PSNR dari 4 citra kanker paru-paru. Secara kuantitatif keberhasilan sebuah metode dapat diketahui dengan membandingkan nilai error piksel dari citra hasil perbaikan dengan citra asli yaitu dengan menghitung nilai MSE dan
PSNR. Keberhasilan sebuah metode dapat diketahui jika nilai MSE rendah dan nilai PSNR tinggi, dua buah citra memiliki tingkat kemiripan yang rendah jika nilai PSNR di bawah 30 dB. Pada Tabel 2 metode histogram equalization diperoleh nilai rata-rata MSE sebesar 949,960 dB dan nilai rata-rata PSNR sebesar 198,853 dB. Sedangkan pada metode contrast limited adaptive histogram equalization diperoleh nilai ratarata MSE sebesar 653,434 dB dan nilai rata-rata PSNR sebesar $245,547 \mathrm{~dB}$.

Perbandingan nilai MSE dapat dilihat pada Gambar 2 mulai dari citra 1 sampai dengan citra 4 metode contrast limited adaptive histogram equalization memiliki nilai MSE lebih rendah dibanding nilai MSE metode histogram equalization. Pada metode histogram equalization, nilai MSE terbesar ada pada citra $1=1.530,4 \mathrm{~dB}$ dan nilai MSE terkecil ada pada citra $4=625,512 \mathrm{~dB}$. Sedangkan pada metode contrast limited adaptive histogram equalization, nilai MSE terbesar ada pada citra $1=1.171,2 \mathrm{~dB}$ dan nilai MSE terkecil ada pada citra $3=$ $396,189 \mathrm{~dB}$.

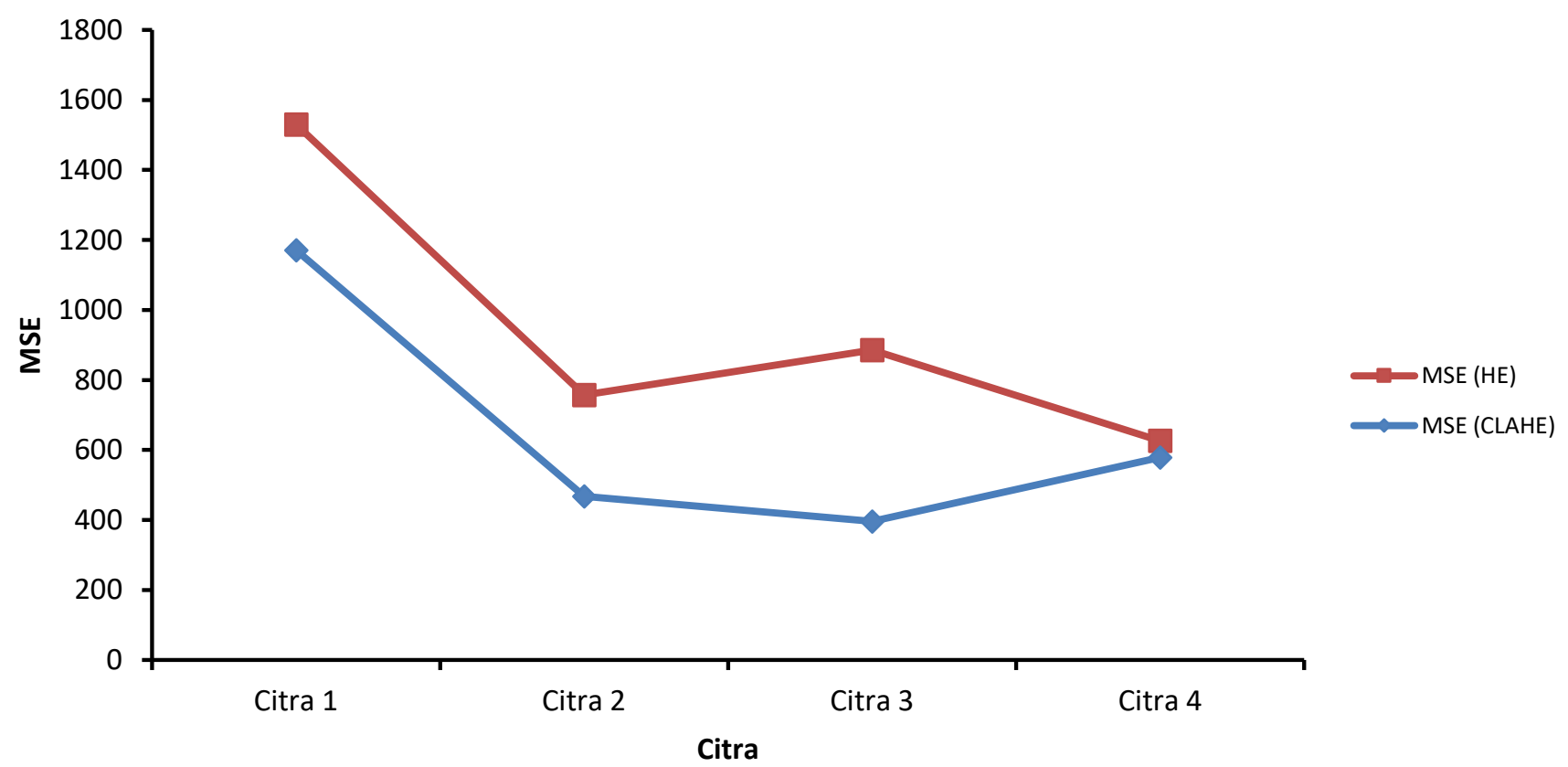

Gambar 2. Perbandingan Nilai MSE 


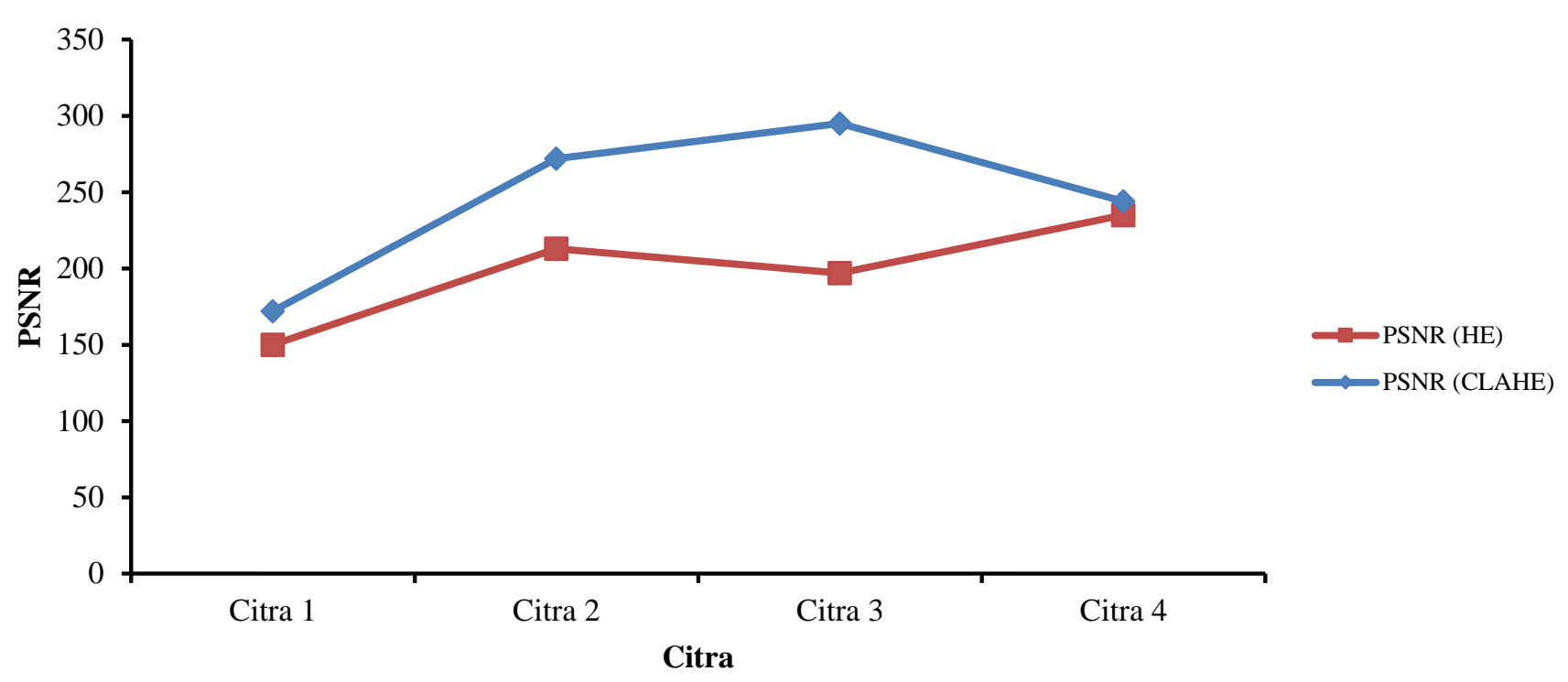

Gambar 3. Perbandingan Nilai PSNR

Sedangkan perbandingan nilai PSNR dapat dilihat pada Gambar 3. Dari gambar dapat diketahui bahwa metode contrast limited adaptive histogram equalization memiliki nilai PSNR yang lebih tinggi dibanding nilai PSNR metode histogram equalization. Pada metode histogram equalization, nilai PSNR terbesar ada pada citra $4=234,768 \mathrm{~dB}$ dan nilai PSNR terkecil ada pada citra $1=150,091 \mathrm{~dB}$. Sedangkan pada metode contrast limited adaptive histogram equalization, nilai PSNR terbesar ada pada citra $3=294,988 \mathrm{~dB}$ dan nilai PSNR terkecil ada pada citra $1=171,569 \mathrm{~dB}$.

\section{KESIMPULAN}

Berdasarkan hasil analisis secara kualitatif dan kuantitatif dapat disimpulkan bahwa metode contrast limited adaptive histogram equalization lebih baik dibanding metode histogram equalization dalam melakukan peningkatan kualitas citra untuk mendeteksi nodul kanker paru-paru.

\section{REFERENSI}

[1] R. A. Syifa, K. Adi and C. E. Widodo, "Analisis Tekstur Citra Mikroskopis Kanker Paru Menggunakan Metode Gray Level CO-Occurance Matrix (GLCM) dan Transformasi Wavelet dengan Klasifikasi Naïve Bayes," Youngster Physics Journal, vol. 5, no. 4, pp. 457-462, 2016.

[2] N. Jawas and I. W. B. Sentana. "Deteksi Lung Nodule Otomatis dari Citra Medis Computed Tomography (CT) Scan dengan Operasi Morfology dan SVM," Jurnal Sistem dan Informatika, vol. 12, no. 2, pp. 140-18, 2018.

[3] R. C. Gonzalez and R. E. Woods, Pedoman Pengendalian Faktor Risiko Kanker Paru. Kementerian Kesehatan RI: Jakarta, 2018.

[4] L. Wulandari and N. E. Faot, "Problem Penegakkan Diagnostik Pasien dengan Massa di Paru,” Internasional Jurnal Respirasi, vol. 3, no. 2, 2017.

[5] I. Iqbalawaty, dkk, "Profil Hasil Pemeriksaan CT-Scan pada Pasien Tumor Paru di Bagian Radiologi RSUD Dr. Zainoel Abidin Periode Juli 2018-Oktober 2018," Original Article, vol. 10, no. 3, pp. 625-630, 2019.

[6] Y. Liu, H. Wang, Y. Gu, and X. Lv, "Image classification
Toward Lung Cancer Recognition by Learning Deep Quality Model," J. Vis. Commun Image Representation, vol.63, 2019.

[7] M. R. Khilmawan and A. A. Riadi, "Implementasi Pengurangan Noise pada Citra Tulang menggunakan Metode Median Filter dan Gaussian Filter," Jurnal Ilmiah Penelitian dan Pembelajaran Informatika, vol. 3, no. 2, pp. 116-121, 2018.

[8] E. M. Azhari, M. Mudzakkir, M. Hatta, Z. Z. Htike, and S. L. Win, "Brain Tumor Detection and Localizationin Magnetic Resonance Imaging," International Journal of Information Technology Convergence and Services, vol. 4, no. 1, 2014.

[9] N. Singh, L. Kaur and K. Singh, "Histogram Equalization Techniques for Enhancement of Low Radiance Retina Images for Early Detection of Diabetic Retinopathy," Engineering Science and Technology an International Journal, vol.22, pp. 736-745, 2019.

[10] D. L. Nasution, "Perbaikan Kualitas Citra Maps Menggunakan Metode Contrast Limited Adaptive Histogram Equalization (CLAHE)," Konferensi Nasional Informasi dan Komputer, vol. 3, no. 1, pp. 49-56, 2019.

[11] I. Maulana and P. N. Andono, "Analisa Perbandingan Adaptif Median Filter dan Median Filter dalam Reduksi Noise Salt \& Pepper," Cogito Smart Journal, vol. 2, no. 2, 2016.

[12] S. D. B. Mau, "Pengaruh Histogram Equalization untuk Perbaikan Kualitas Citra Digital,” Jurnal SIMETRIS, vol. 7, no.1, 2016.

[13] N. Ahmad and A. Hadinegoro, "Metode Histogram Equalization untuk Perbaikan Citra Digital," Seminar Nasional Teknologi Informasi dan Komunikasi Terapan, 2012.

[14] A. A. Riadi, A. A. Chamid and A. Sokhibi, "Analisis Komparasi Metode Perbaikan Kontras Berbasis Histogram Equalization pada Citra Medis ,"Jurnal SIMETRI, vol. 8, no. 1, 2017.

[15] D-Chun Wu a and W-Hsing Tsai, 2003, "A steganographic metod for images by pixel-value differencing", Patern Recognition Letters, Volume 24, 1613 - 1626.

[16] M. Sundaram, K. Ramar, N. Arumugam and G. Prabin, 2011. "Histogram Modified Local Contrast Enhancement for Mammogram Image", Applied Soft Computing 11 (2011) 5809-5816.

[17] H. R. Fajrin, "Perbandingan Metode untuk Perbaikan Kualitas Citra Mammografi," Jurnal SIMETRIS, vol. 7, no. 2, 2016. 